Celal Bayar University Journal of Science

\title{
Compatibility Studies of Sildenafil with Different Excipients by Using TGA, DSC, XRD and FTIR
}

\author{
Hale Seçilmiş Canbay ${ }^{1 *}$, Mahmut Doğantürk ${ }^{2}$ \\ ${ }^{1}$ Department of Bioengineering, Faculty of Engineering and Architecture, Burdur Mehmet Akif Ersoy University, \\ Burdur, Turkey \\ ${ }^{2}$ Research and Practice Center, Burdur Mehmet Akif Ersoy University, Burdur, Turkey \\ *halecanbay@mehmetakif.edu.tr
}

Received: 1 September 2019

Accepted: 12 December 2019

DOI: $10.18466 /$ cbayarfbe.613951

\begin{abstract}
Study of drug-excipient interactions is a crucial step in preformulation stage of drug development to achieve consistent chemical, physical, bioavailability, manufacturability and stability of the dosage form. In pre-formulation studies, it is important to use thermoanalytical and spectroscopic methods. These are important systems for achieving a suitable formulation. Sildenafil is a well-tolerated and highly effective treatment for erectile dysfunction. Erectile dysfunction was revolutionized with the development of a selective inhibitor of cyclic guanosine monophosphate-specific phosphodiesterase type 5 . Thermogravimetric analysis, Differential Scanning Calorimetry, Fourier Transform Infrared Spectroscopy, and X-ray Powder Diffraction systems were used in the investigation and to determine the possible interactions between sildenafil and some excipients like butylated hydroxyanisole, cellulose, sodium carboxymethyl cellulose, ascorbic acid, and citric acid. Binary mixtures of drug:excipient=1:1 (mass/mass) have been analyzed. According to the results, there is incompatibility with butylated hydroxyanisole, ascorbic acid, and citric acid.
\end{abstract}

Keywords: Sildenafil, compatibility, excipient, TGA, FTIR, DSC, XRD.

\section{Introduction}

Erectile dysfunction (ED) is defined as inability to provide or maintain a satisfactory erection for sexual activity [1]. For an erection, nitric oxide and cyclic guanosine monophosphate are mediated by the relaxation of the corpora cavernos of the penis with non-cholinergic adrenergic receptors. Inhibition of phosphodiesterase type 5 (PDE5) isoenzyme provides increased institutional cyclic guanosine monophosphate (cGMP) levels and an increased penile erection.guanosine monophosphate levels and an increased penile erection [2].With the development of PDE5 inhibitors such as sildenafil, ED treatment and enhanced nitrergic cavernosal relaxation have been provided [3]. Sildenafil is an orally administered and selective inhibitor of phosphodiesterase type 5 (PDE5), a drug approved for the treatment of erectile dysfunction in about 50 countries [4-5].

Investigation of drug-excipient compatibility is an important step in the pre-formulation phase of drug development. This step is very important because of potential interactions between drugs and excipients, stable dosage form, chemical, physical, formulation, bioavailability and stability determination. They contribute significantly to avoidance of expensive material waste and to monitor and characterize incompatibility with pharmaceutical excipients. The combined use of various techniques provides an indepth understanding of drug-excipient interactions. In addition, the dosage form assists in the selection of suitable excipients in its design [6-11].

The current literature shows that incompatibility studies between the drug-excipient can be performed by Thermogravimetric Analysis (TGA), Differential Scanning Calorimetry (DSC), Fourier Transform Infrared Spectroscopy (FTIR), X-ray Diffraction (XRD) systems [8, 12, 13]. Furthermore, there is insufficient study to investigate the excipient compatibility of sildenafil. Sildenafil- excipient interaction has not been studied sufficiently. The aim of our study is to contribute to the literature for this purpose. 


\section{Materials and Methods}

\subsection{Chemicals and Reagents}

Sildenafil citrate, butylated hydroxyanisole (BHA), cellulose (C), sodium carboxymethyl cellulose (SCC), ascorbic acid (AA) and citric acid (CA) were obtained from Sigma and Merck. IR Grade Potassium bromide $(\mathrm{KBr})$ was obtained from Merck. The chemical structure of Sildenafil is given in Figure 1.

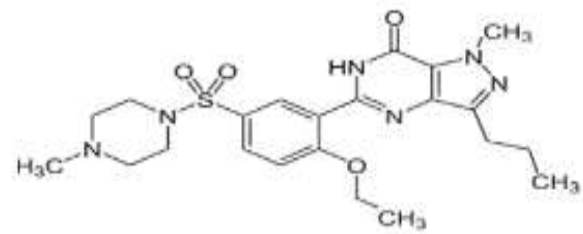

Figure 1. The chemical structure of Sildenafil.

\subsection{Measurement by Thermogravimetric Analysis (TGA) System}

Thermogravimetry, derivative TG (DTG) and DTA curves of the thermal decomposition of sildenafil and excipients. Results were obtained using a model TG/DTA 7200 (SEIKO SII, MA, USA). Approximately $10 \mathrm{mg}$ samples were placed in platinum pans and heated in the dry nitrogen at a rate of $10^{\circ} \mathrm{C} \mathrm{min}^{-1}$ up to a final temperature of $600^{\circ} \mathrm{C} . \alpha-\mathrm{Al}_{2} \mathrm{O}_{3}$ was employed as a reference material in the analysis.

\subsection{Measurement by Differential Scanning Calorimetry (DSC)}

Differential Scanning Calorimetry (Perkin Elmer DSC 4000, Waltham, MA, USA) was used for thermal analysis [14]. Individual samples (drug and excipients) were weighed to approximately $10 \mathrm{mg}$ directly in the pierced DSC aluminum pan [6]. The sample pan was crimped for effective heat conduction and scanned in the temperature range of $-20-400^{\circ} \mathrm{C}$ at a rate of $10^{\circ} \mathrm{C}$ $\min ^{-1}$ under an atmosphere of dry nitrogen [15].

\subsection{Measurement by Fourier-Transform Infrared Spectroscopy (FT-IR)}

Frontier spectrometer (Perkin Elmer, Waltham, MA, USA) was used. Drug and selected excipient (1:1 ratio, w/w) mixture can be placed directly into the path of the infrared beam and 128 scans were collected with a resolution of $4 \mathrm{~cm}^{-1}$ for each measurement over the spectral range of $400-4000 \mathrm{~cm}^{-1}$. $\mathrm{KBr}$-pressed disk technique was used. $10 \mathrm{mg}$ of drug + excipient mixture sample and $100 \mathrm{mg}$ of potassium bromide were weighted. Samples were mixed in agate mortar. And then pressed for 5 minutes at 10 tones $/ \mathrm{cm}^{2}$ to form a semitransparent pellet which lets light to be transmitted to the detector $[16,17]$.
2.5. Measurement by X-ray Powder Diffraction (XRD)

X-ray diffraction (XRD) patterns of the individual samples (drug and excipients) were analyzed using a Bruker AXS D8 Advance X-ray diffractometer (MA, USA).

\section{Results and Discussion \\ 3.1. Thermal Analysis}

The thermoanalytical curves (DTA-TGA) of Sildenafil is illustrated in Figure 2.

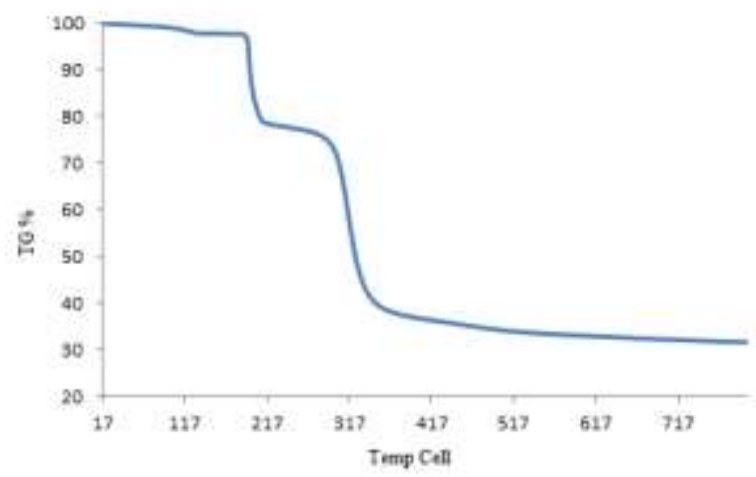

Figure 2. TG curves of Sildenafil citrate.

Sildenafil citrate lost just about $2.5 \%$ of its mass due to dehydration. In the temperature range of 185 to $230^{\circ} \mathrm{C}$, SC corresponds to about $22.0 \%$ citric acid evaporation. After heating to 185 to $230^{\circ} \mathrm{C}$, the remaining phase belongs to the Sildenafil structure, which begins the second separation. After $400^{\circ} \mathrm{C}$, a low and continuous loss of mass is related to the formation of elemental carbon in an inert nitrogen atmosphere [18, 19]. The data obtained are similar to the studies on Sildenafil [18, 19].The compatibility of Sildenafil with the different excipient used BHA, C, SCC, AA, CA were studied using TGA. In the TGA thermogram of the Sildenafil-C mixture, as with Sildenafil citrate, there was a mass loss of $180-230^{\circ} \mathrm{C}$ The rate of loss of mass is lower. Continuous and low mass loss continued after $400^{\circ} \mathrm{C}$. In the TGA thermogram of the Sildenafil-SCC mixture, there was a mass loss of $180-230^{\circ} \mathrm{C}$. The mass loss rate is close to Sildenafil citrate. After $400^{\circ} \mathrm{C}$, continuous mass loss continued. However, the slope of the peak is different from Sildenafil citrate. In the TGA thermogram of the sildenafil-BHA mixture, the first mass loss started at about $85^{\circ} \mathrm{C}$. Mass loss in sildenafilAA showed a different decay graph, although about $150^{\circ} \mathrm{C}$ started. In the TGA thermogram of the sildenafilCA mixture, the mass loss range is around $140-230^{\circ} \mathrm{C}$. The thermograms obtained from these three excipient mixtures are different from Sildenafil citrate. The thermoanalytical curves (DTA-TGA) of Sildenafilexcipient mixtures are illustrated in Figure 3. 

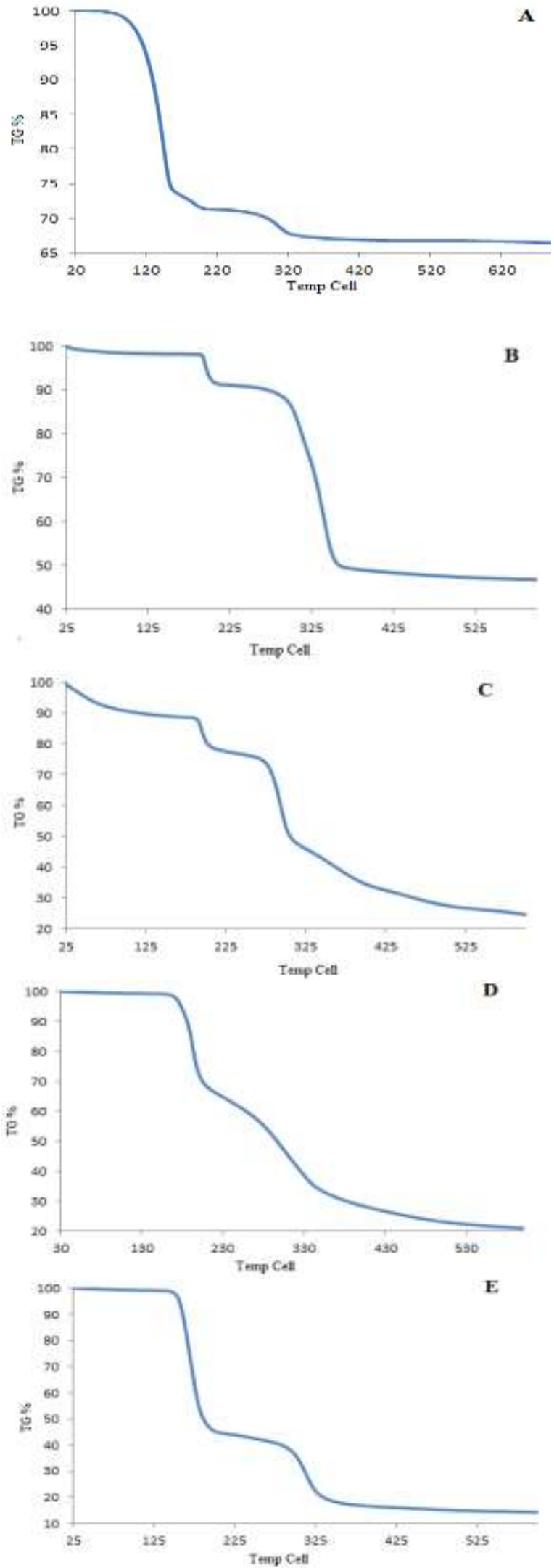

Figure 3. TG curves of Sildenafil-excipient mixture: A. Sildenafil-BHA; B. Sildenafil-C; C. Sildenafil-SCC; D Sildenafil-AA; E. Sildenafil-CA.
DSC curves of Sildenafil citrate is available in Figure 4.

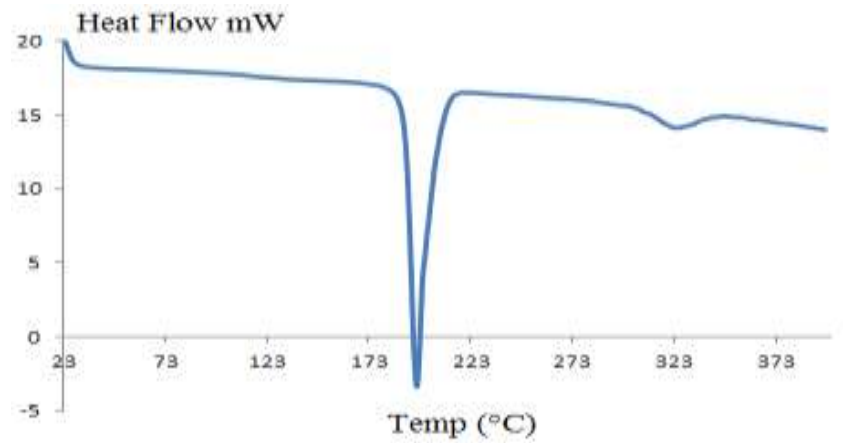

Figure 4. DSC curves of Sildenafil citrate.

The DSC curve of SC showed a sharp endothermic event at $196.63^{\circ} \mathrm{C}$. This result shows that SC does not show decomposition up to $230^{\circ} \mathrm{C}$ and this temperature range is perfect for conducting the compatibility analysis with DSC method.

Table 1. Peak temperature values of Sildenafilexcipient physical mixtures

\begin{tabular}{ccc}
\hline Sample & $\begin{array}{c}\text { Drug-excipient } \\
\text { ratio }\end{array}$ & $\mathbf{T}_{\text {peak }}\left({ }^{\circ} \mathbf{C}\right)$ \\
\hline Sildenafil & - & $\mathbf{1 9 6 . 6 3}$ \\
Sildenafil-BHA & $1: 1$ & $\mathbf{6 0 . 8 2}$ \\
Sildenafil-C & $1: 1$ & $\mathbf{2 0 0 . 4 4}$ \\
Sildenafil-SCC & $1: 1$ & $\mathbf{1 9 6 . 6 9}$ \\
Sildenafil-AA & $1: 1$ & $\mathbf{1 7 0 . 1 0}$ \\
Sildenafil-CA & $1: 1$ & $\mathbf{1 5 0 . 4 9}$ \\
\hline
\end{tabular}

The compatibility of Sildenafil with the different excipient used BHA, C, SCC, AA, CA were studied using DSC. DSC curve showed an endothermic peak at $196.63^{\circ} \mathrm{C}$ for Sildenafil corresponding to the melting temperature point. Similar melting endotherm peak was observed for the Sildenafil-C $\left(200.44^{\circ} \mathrm{C}\right)$ and Sildenafil-SCC $\left(196.69^{\circ} \mathrm{C}\right)$ physical mixtures (Table 1). The low impurities of each component in the mixture caused a slight change in the melting endothermic peak of Sildenafil. This result confirms that there is no interaction between the Sildenafil and C, and SCC. The endotherm of Sildenafil-BHA at $60.82^{\circ} \mathrm{C}$; Sildenafil-AA at $170.10^{\circ} \mathrm{C}$ and Sildenafil-CA at $150.49^{\circ} \mathrm{C}$. This is indicative of a possible drug-excipient interaction. DSC curves of Sildenafil-excipient mixtures are illustrated in Figure 5. 

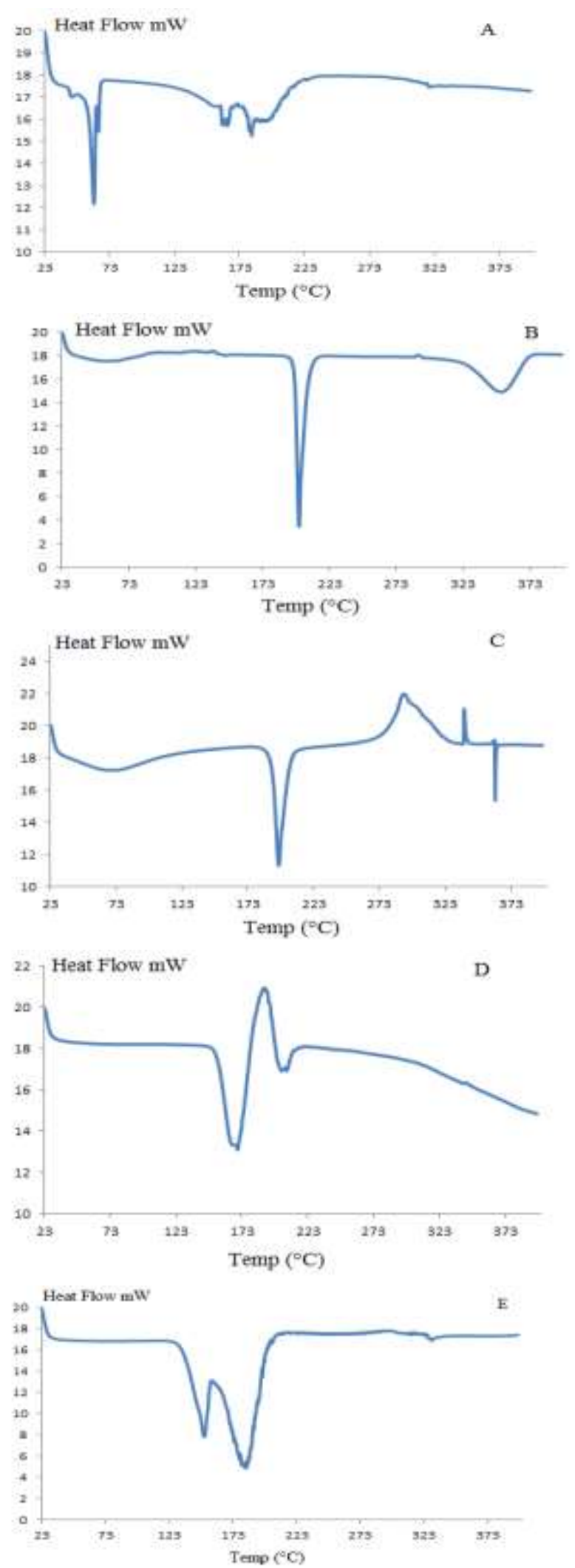

Figure 5. DSC curves of Sildenafil-excipient mixture: A. Sildenafil-BHA; B. Sildenafil-C; C. Sildenafil-SCC; D. Sildenafil-AA; E. Sildenafil-CA.

\subsection{Spectral Analysis}

The infrared spectrum of any compound provides information about the functional groups present in a given compound. Spectra of a drug and drug-excipient mixture are taken using the $\mathrm{KBr}$ method. In our study, various peaks in the IR spectrum were interpreted for the presence of different groups in the structure of the drug (Table 2).

Table 2. FTIR description of sildenafil

\begin{tabular}{l}
$\begin{array}{l}\text { Peak } \\
\text { wavenumber } \\
\left(\mathrm{cm}^{-1)}\right.\end{array}$ \\
\hline
\end{tabular}

3300

Secondary amides (N-H stretching) vibrations

1650-1580 The N-H bending vibrations

$3100-3000$

$=\mathrm{C}-\mathrm{H}$ stretching in an aromatic ring

$3000-2900$

$-\mathrm{C}-\mathrm{H}$ stretchings in the alkanes

1703

$\mathrm{C}=\mathrm{O}$

1600-1585 and carbon-carbon stretching vibrations

1500-1400 in the aromatic rings

1359 asymmetric stretch of the $\mathrm{S}=\mathrm{O}$

1172 symmetrical stretching of the $\mathrm{S}=\mathrm{O}$

$1300-1000$

C-N stretching

$1200-1000$

C-H deformation

It can be seen that in the FTIR spectrum of the sildeafil and Sildeafil-BHA, Sildeafil-C, Sildeafil-SCC, Sildeafil-AA, and Sildeafil-CA binary active drugexcipient mix. The characteristic peaks of Sildenafil have reduced the intensity with shifting fluctuations in either Sildenafil-BHA, Sildenafil-AA and SildenafilCA. (Figure 6). 

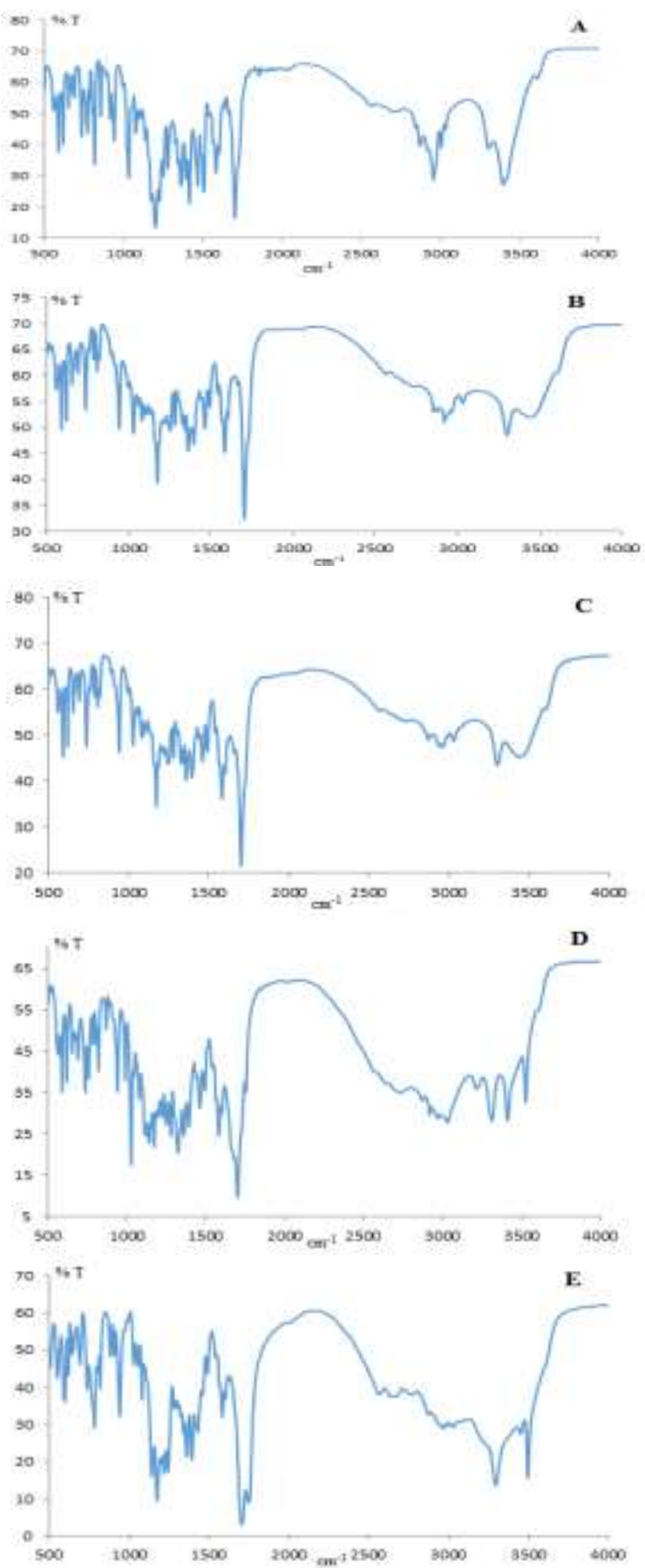

Figure 6. FTIR spectrums of Sildenafil-excipient mixture: A. Sildenafil-BHA; B. Sildenafil-C; C. Sildenafil-SCC; D. Sildenafil-AA; E. Sildenafil-CA.

\subsection{XRD Analysis}

Figure 7, shows the XRD pattern of sildenafil. The XRD pattern of plain drug exhibited sharp, intense, and less diffused peaks at 2 theta angels of 7.4, 8.1, 10.2, $13.1,14.4,16.2,17.5,19.8,20.6,22.7,24.4,22.7$, and $28.5^{\circ}$ indicating the high crystalline nature of Sildenafil (Figure 7). The XRD pattern of the optimized Sildenafil-BHA, Sildenafil-AA and Sildenafil-CA showed major changes including peak disappearance and decreased intensities with attenuated diffraction at same diffraction angles ascertain the solid-state transformation of Sildenafil (Figure 8). These results are in accordance with that recorded by TGA, DSC, and FTIR studies.

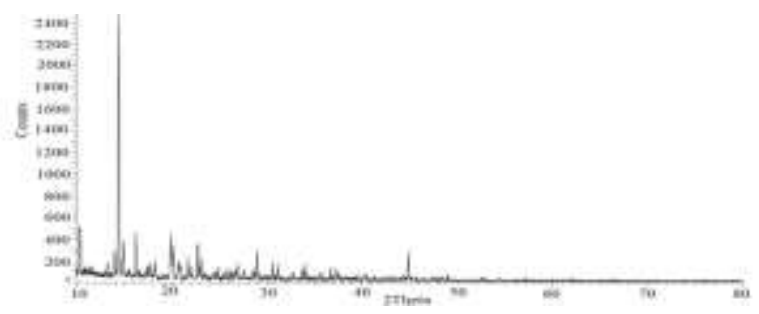

Figure 7. XRD patterrns of Sildenafil.

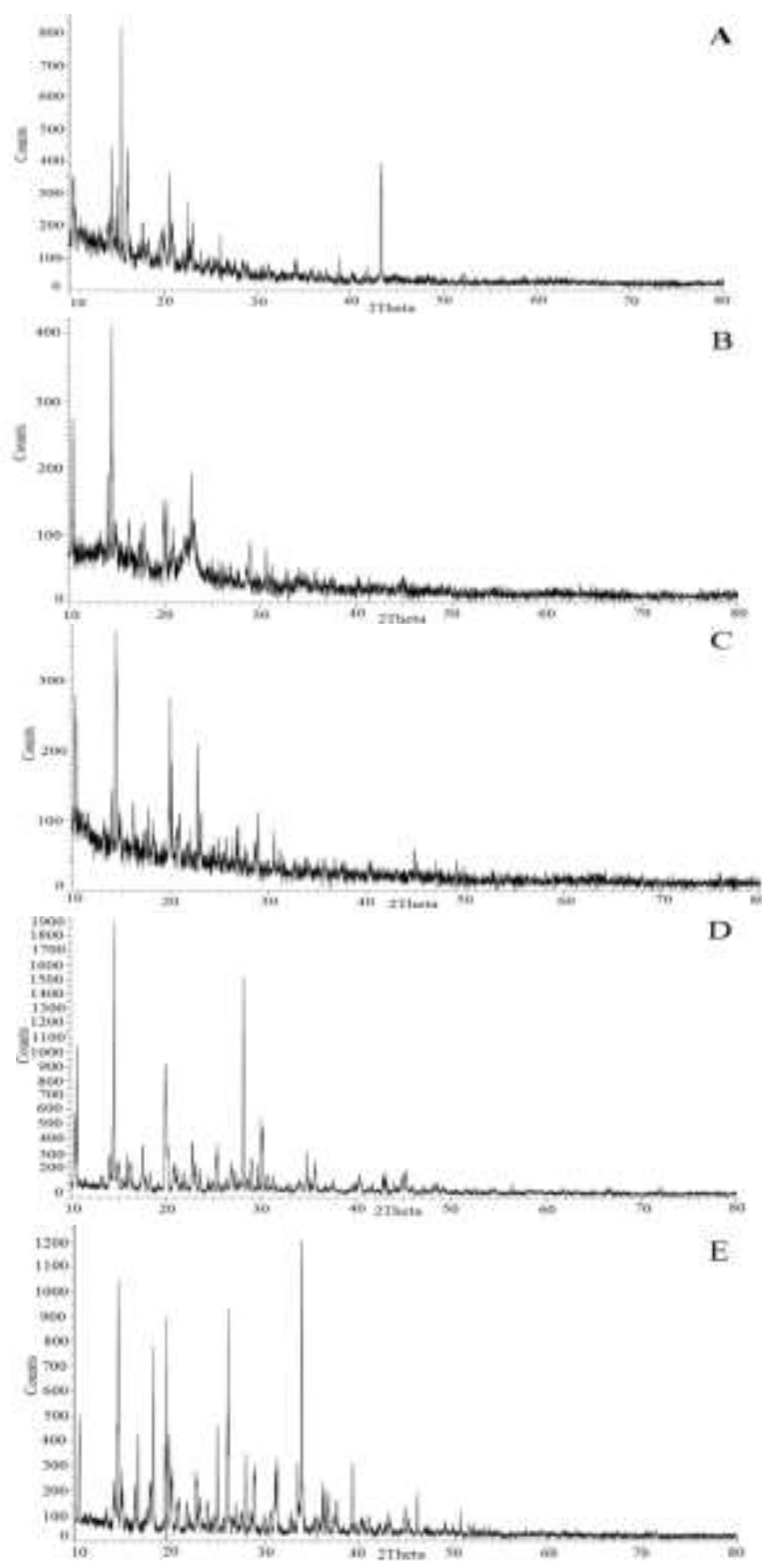

Figure 8. XRD patterrns of Sildenafil-excipient mixture: A. Sildenafil-BHA; B. Sildenafil-C; C. Sildenafil-SCC; D. Sildenafil-AA; E. Sildenafil-CA. 


\section{Conclusion}

Sildenafil is an approved drug for the treatment of erectile dysfunction. It is an orally administered selective phosphodiesterase type 5 (PDE5) inhibitor. Thermal and spectroscopic techniques are highly preferred techniques in drug-excipient studies. In this study, DSC, TGA, FTIR and XRD systems were used to determine the possible interactions between Sildenafil and some excipients like BHA, C, SCC, AA and CA. According to the results obtained from the binary mixtures, there is incompatibility with sildenafil-BHA, Sildenafil-AA and Sildenafil-CA. In the light of the results obtained, it is possible to focus on the compatibility of the excipients in the publication in the following experimental studies. In addition, studies on different drug-excipient ratios and storage life can be done.

\section{Ethics}

There are no ethical issues after the publication of this manuscript.

\section{References}

1. Lue, T.F. 2000. Erectile dysfunction, The New England Journal of Medicine; 342: 1802-1813.

2. McMahon, C.G. 2002. High dose sildenafil citrate as a salvage therapy for severe erectile dysfunction. International Journal of Impotence Research; 14: $533-$ 538.

3. Özgür, C.Ö, Gonenc, F, Yazicioglu, A.H. 2009. Sildenafil or vardenafil nonresponders' erectile response to Tadalafil, Urology Journal; 6.4: 267-271.

4. Boolell, M, Allen, M.J, Ballard, S.A, Gepi-Attee, S, Muirhead, G.J, Naylor, A.M, Osterloh, I.H, Gingell, C. 1996. Sildenafil: an orally active type 5 cyclic GMPspecific phosphodiesterase inhibitor for the treatment of penile erectile dysfunction. International Journal of Impotence Research; 8: 47-52.

5. Webb, D.J, Freestone, S, Allen, M.J, Muirhead, G.J. 1999. Sildenafil citrate and blood-pressure-lowering drugs: Results of drug interaction studies with an organic nitrate and a calcium antagonist. The American Journal of Cardiologyt; 83. 5A: 21C-28C.

6. Verma, R.K, Garg, S. 2005. Selection of excipients for extended release formulations of glipizide through drug-excipient compatibility testing, Journal of Pharmaceutical and Biomedical Analysis; 38. 4: 633644.

7. Fathima, N, Mamatha, T, Qureshi, H.K, Anitha, N, Rao, J.V. 2011. Drug-excipients interaction and its importance in dosage form development. Journal of Applied Pharmaceutical Science; 1. 6: 66-71.

8. Bozag Pehlivian, S, Subaşi, B, Vural, I, Unlü, N, Capan, Y. 2011. Evaluation of drug-excipient interaction in the formulation of celecoxib tablets. Acta Poloniae Pharmaceutica; 68: 423-433.

9. Murthy, T.E.G.K, Bala Vishnu Priya M, Suresh Babu V.V. 2012. Compatibility studies of Acetazolamide with excipients by using High performance liquid chromatography. Indian drugs; 49. 05: $39-45$.

10. Prathyusha, C.H, Murthy, T.E.G.K. 2013. Compatibility studies of Donepezil with different excipients by using HPLC and FTIR. Journal of Advanced Pharmacy Education \& Research; 3. 3: 273-278.

11. Tulasi Baru, R, Bitla, P. 2017. Cyclobenzaprine drug assay and cyclobenzaprine-excipient interaction studyby chromatography, thermal and spectral analysis. Journal of Pharmaceutical Chemistry \& Chemical Science; 1. 1: 1-9.

12. McDaid, F.M, Barker, S.A, Fitzpatrick, S, Petts, C.R, Craig, D.Q.M. 2003. Further investigations into the use of high sensitivity differential scanning calorimetry as a means of predicting drug-excipient interactions. The International Journal of Pharmaceutics; 252. 1: 235-240.

13. Seçilmiş Canbay, H, Polat, M, Doğantürk, M. 2019. Study of stability and drug-excipient of estriol. Bilge International Journal of Science and Technology Research; 3. 2: 102-107.

14. Monajjemzadeh, F, Hassanzadeh, D, Valizadeh, H, Siahi-Shadbad, M.R, Mojarrad, J.S, Robertson, T.A, Roberts, M.S. 2009. Compatibility studies of acyclovir and lactose in physical mixtures and commercial tablets. The European Journal of Pharmaceutics and Biopharmaceutics; 73: 404-413.

15. Wakasawa, T, Sano, K, Hirakura, Y, Toyooka, T, Kitamura, S. 2008. Solid-state compatibility studies using a high-throughput and automated forced degradation system. The International Journal of Pharmaceutics; 355: 164-173.

16. Madejová, J. 2003. FTIR techniques in clay mineral studies. Vibrational Spectroscopy, 31. 1: 1-10.

17. Ohannesian, L, Streeterhandbook, A.J. 2002. Handbook of Pharmaceutical Analysis. Marcel Dekker, New York, NY, USA. 
18. Melnikov, P, Corbi, P.P, Cuin, A, Cavicchioli, M, Guimarães, W.R. 2003. Physicochemical properties of sildenafil citrate (Viagra) and sildenafil base. Journal of Pharmaceutical Sciences; 92: 2140-2143.

19. Júlio, T.A, Zâmara, I.F, Garcia, J.S, Trevisan, M.G. 2013. Compatibility of sildenafil citrate and pharmaceutical excipients by thermal analysis and LCUV. Journal of Thermal Analysis and Calorimetry; 111: 2037-2044.
20. Yathirajan, H.S, Nagaraj, B, Nagaraja, P, Bolte, M. 2005. Sildenafil citrate monohydrate, Acta Crystallographica Section E; E61: 0489-0491.

21. Sawatdee, S, Pakawatchai, C, Nitichai, K, Srichana, T, Phetmung, H. 2015. Why sildenafil and sildenafil citrate monohydrate crystals are not stable?. Saudi Pharmaceutical Journal; 23: 504-514. 